\title{
Inhaled corticosteroids and growth of airway function in asthmatic children
}

\author{
P.J.F.M. Merkus*, W. van Pelt ${ }^{\#}$, J.C. van Houwelingen ${ }^{\Uparrow}$, L.E.M. van Essen-Zandvliet ${ }^{+}$, E.J. Duiverman ${ }^{\S}$, \\ K.F. Kerrebijn*,f, P.H. Quanjer**,f
}

Inhaled corticosteroids and growth of airway function in asthmatic children. P.J.F.M. Merkus, W. van Pelt, J.C. van Houwelingen, L.E.M. van Essen-Zandvliet, E.J. Duiverman, K.F. Kerrebijn, P.H. Quanjer. (C) ERS Journals Ltd 2004.

ABSTRACT: Airway inflammation and remodelling play an important role in the pathophysiology of asthma. Remodelling may affect childhood lung function, and this process may be reversed by anti-inflammatory treatment. The current study assessed longitudinally whether asthma affects growth of airway function relative to airspaces, and if so whether this is redressed by inhaled corticosteroids (ICS).

Every 4 months for up to 3 yrs, lung function was assessed in 54 asthmatic children (initial age 7-16 yrs), who inhaled $0.2 \mathrm{mg}$ salbutamol t.i.d. and $0.2 \mathrm{mg}$ budesonide t.i.d. $\left(\beta_{2}\right.$-agonist (BA) $\left.+\mathrm{ICS}\right)$, or placebo $(\mathrm{PL})$ t.i.d. $(\mathrm{BA}+\mathrm{PL})$ in a randomised, double-blind design. Measurements were carried out before and after maximal bronchodilation. Airway growth was assessed from the change of forced expiratory volume in one second and of maximal expiratory flows (at $60 \%$ and $40 \%$ of total lung capacity (TLC) remaining in the lung) relative to TLC, as measures of more central, intermediate and more peripheral airways. Growth patterns were compared with the longitudinal findings in 376 healthy children.

Airway patency after maximal bronchodilation in patients on $\mathrm{BA}+\mathrm{PL}$ remained reduced compared to healthy subjects, whereas in patients on BA+ICS a marked improvement was observed to subnormal. No differences between patients and controls could be demonstrated for growth patterns of central and intermediate airway function. Compliance with BA+ICS was $75 \%$ of the prescribed dose, resulting in significant, sustained improvement of symptoms and postbronchodilator calibre of central and intermediate airways to subnormal within 2 months, but postbronchodilator small airway patency remained reduced, though improved compared to patients on BA+PL.

Anti-inflammatory treatment of asthmatic children is associated with normal functional development of central and intermediate airways. The persistently reduced postbronchodilator patency of peripheral airways may reflect remodelling, or insufficient anti-inflammatory treatment.

Eur Respir J 2004; 23: 861-868.
*Division of Respiratory Medicine, Dept of Pediatrics, Erasmus University Medical Center, Sophia Children's Hospital, Rotterdam, ${ }^{\#}$ National Institute of Public Health and the Environment, Bilthoven, "Dept of Biostatistics and ${ }^{* *}$ Physiology Dept, Leiden University Medical Center, Leiden, ${ }^{+}$Asthma Center Heideheuvel, Hilversum, ${ }^{\S}$ Division of Respiratory Medicine, Dept of Pediatrics, Groningen University Medical Center, Groningen, the Netherlands. ${ }^{f}$ Formerly of these institutions.

Correspondence: P.J.F.M. Merkus, Sophia Children's Hospital, Erasmus University Medical Center Rotterdam, P.O. Box 2060, 3000 CB Rotterdam, The Netherlands.

Fax: 31104636772

E-mail: p.j.f.m.merkus@erasmusmc.nl

Keywords: Airway function

asthma

bronchodilation

inhaled corticosteroids

lung growth

remodelling

Received: March 202003

Accepted after revision: January 52004

This study was supported by the Netherlands Health Research Promotion Program (SGO).
Distinct histopathological changes occur in the central airways of children with mild [1] to severe [2, 3] asthma, but the direct relationship between such structural alterations and functional deterioration is unclear. Although between $30-70 \%$ of asthmatic children improve or "grow out of asthma" in late adolescence or early adulthood [4-7], young asthmatic patients who have become asymptomatic may still have residual histological abnormalities [8,9], airways obstruction [6, 10, 11], and elevated lung volumes [6, 12-14]. Furthermore, the decline of lung function with ageing in adult asthmatics appears to occur at a greater rate than in nonasthmatic subjects $[5,7$, 15] and long-standing asthma may be difficult to distinguish from chronic bronchitis and chronic obstructive pulmonary disease (COPD) [16, 17]. These findings, and the concept of asthmatic airway remodelling [1-3, 9, 18-20] suggest that asthma is associated with progressive functional changes that start in childhood, continue into adulthood, and may end in COPD with a substantial irreversible component. Indeed, some studies suggest that early intervention may favour longterm outcome of lung function [21-23], although this was

For editorial comments see page 795. not based on lung function data obtained after maximal bronchodilation.

Airways obstruction throughout childhood asthma may be due to factors such as diminished lung growth [24, 25], enhanced bronchomotor tone and/or airway wall thickening and remodelling due to airway inflammation. A longitudinal study with maximal post-bronchodilator data would be required to look into diminished airway growth, taking into account any effects of anti-inflammatory drugs on lung growth. Several prospective longitudinal studies that assessed the effect of childhood asthma on the development of lung function [5, 6, 11, 14] describe reduced expiratory flows compared to normal subjects after correction for height and/ or age $[5,6,11,14]$, that could not always be detected by measuring forced expiratory volume in one second (FEV1) [6, $11,14]$. One should be cautious to infer from these studies that lung growth is diminished in asthma. First, conclusions were based on prebronchodilator data so that enhanced bronchomotor tone and/or inflammation were not ruled out. Secondly, using reference equations rather than healthy controls may introduce artefacts: the relationship between height and lung function during puberty is complex [26, 27], 
and a delayed pubertal growth spurt in asthmatics [28] may introduce additional problems. Thirdly, total lung capacity (TLC), and not forced vital capacity (FVC), should be used as a measure of lung size because residual volume (RV)/TLC depends on sex and increases with age during puberty [29-31], and because airway closure in asthmatic children may be more pronounced than in controls [29, 30].

The aim of the present study was to investigate the growth of airways and airspaces in children with moderate asthma who were treated at random with inhaled placebo or corticosteroids in a fixed dose, irrespective of symptoms. Prospective lung function measurements were obtained prior to and after maximal bronchodilation during a median period of 22 months. This study was part of a large multicentre intervention study carried out between 1988-1992, which demonstrated that anti-inflammatory treatment in childhood asthma results in an improvement in symptoms, exacerbation rates, hospital admissions, and bronchial hyperresponsiveness [32]. The current study used measures of airway function, expressed as a per cent of TLC to correct for lung size, to avoid spurious results due to differences between the sexes. Sex-specific reference equations were not used because of the artefacts that occur during the pubertal growth spurt [26, 27]. The present authors assumed that airflow limitation during a forced expiration reflects wave speed flow in progressively more distal airways during the expiration, and that FEV1, maximum expiratory flow at $60 \%$ of TLC (MEF60\%TLC), and $\mathrm{MEF} 40 \% \mathrm{TLC}$ reflect airway patency when choke points are located in more central (trachea and main bronchi) airways, intermediate (2nd and 3rd generation) airways and in more distal (4th-6th generations) airways, as was measured intrabronchially in adults with severe asthma and in healthy controls [33]. Airway function was corrected for lung size (TLC) and compared with those obtained in a large longitudinal study in nonsmoking Dutch children without respiratory symptoms [26, 29].

\section{Material and methods}

\section{Subjects}

The study subjects consisted of asthmatic patients who participated in a clinical trial [32], and were recruited between 1988 and 1992 from the outpatient clinics for respiratory medicine of the Juliana Children's Hospital, The Hague, and the Rotterdam University Hospital/Sophia Children's Hospital. Inclusion criteria were: 1) moderate to moderately severe asthma [34], defined as a history of chronic or episodic shortness of breath, wheeze and/or cough; 2) FEV1 55-90\% of predicted [35] and/or FEV1/FVC $50-75 \%$; 3) a provocative dose of histamine that caused a reduction in FEV1 by $20 \%$ $(\mathrm{PD} 20)<150 \mu \mathrm{g}$; 4) ages $7-16 \mathrm{yrs}$. The reference population comprised 287 male and 89 female children who participated in a longitudinal study and who had had no respiratory symptoms prior to and during that study [26, 31]. Every 6 months for up to $7 \mathrm{yrs}$ anthropometric and lung function data were obtained. Informed consent was obtained from participants and their parents, and the local medical ethics committees approved the study.

\section{Design}

Prior to the study, corticosteroid or cromones were tapered off. During the 4 week run-in period medication consisted of inhaled $\beta_{2}$-agonist (BA) on demand. Next, baseline lung function was assessed and patients were randomly allocated to one of two treatment arms with stratification for sex, age, hospital and prior use of inhaled corticosteroid (ICS) and/or cromoglycate [32]. Double-blind inhalation medication consisted of salbutamol $0.2 \mathrm{mg}$ plus budesonide $0.2 \mathrm{mg}$ t.i.d. $(\mathrm{BA}+\mathrm{ICS})$ or placebo (PL) t.i.d. (BA+PL) via a spacer (Volumatic $\mathbb{R}$ ). For the purpose of this study, all cannisters were of the same design to fit into the same spacer. Additional inhaled fenoterol was allowed up to 4 times daily. When more than four courses of prednisolone were needed in 12 months, patients were withdrawn from the study. Compliance with therapy was estimated from canister weight loss.

\section{Maximal bronchodilation and lung function measurements}

In patients, maximum expiratory flow volume (MEFV) curves and measurements of total lung capacity (TLC) were obtained once every 4 months for up to $3 \mathrm{yrs}$, before and $20 \mathrm{~min}$ after bronchodilation achieved with 2 sequential inhalations of $(800+200) \mu \mathrm{g}$ salbutamol at $20 \mathrm{~min}$ intervals, using a spacer (Volumatic (B) [36]. From a previous study in 78 asthmatic children (age range: 9-18 yrs) with a baseline FEV1 ranging from 41 to $109 \%$ pred, it was concluded that this dosage was sufficient to obtain maximal bronchodilation. After 1,000 $\mu \mathrm{g}$ salbutamol, a plateau was reached in the dose/ response curve for all parameters from the MEFV curve, with values that did not differ from those obtained after 1,200 $\mu \mathrm{g}$ salbutamol, and this occurred irrespective of severity of airways obstruction (personal communication: P.J.F.M. Merkus, Sophia Children's Hospital, Erasmus University Medical Center, Rotterdam, The Netherlands). In healthy controls composite MEFV-curves were constructed using the same protocol as in patients [26]. RV and TLC were determined by the nitrogen forced re-breathing technique which has been validated in subjects with [37] and without [38] airways obstruction.

\section{Development of airway function in asthma}

In healthy controls and in asthmatic patients, MEF60\%TLC and MEF40\%TLC remaining in the lung were calculated through interpolation of MEFV data superimposed on TLC. Development of pulmonary function with age was assessed from FEV1\%TLC, MEF60\%TLC and MEF40\%TLC as measures of central, intermediate and peripheral airway calibre, respectively. RV and FEV1 were expressed as the per cent of TLC, and MEF60\%TLC and MEF40\%TLC were expressed in TLC per second, to correct for lung size.

\section{Data analysis}

Healthy subjects were included in the analyses if their follow-up lasted at least 18 months. Patient data were analysed if the follow-up was at least $1 \mathrm{yr}$ while on the same treatment. Subjects were excluded from the analyses when no significant growth of TLC was observed due to too few data points, or at the end of puberty (defined as variation smaller than the single measurement reproducibility [37]). Development of pulmonary function with age within individuals was studied from least squares regression. This was done after verification that the distributions of the data and the residuals were normal and homoscedastic, respectively. Measurement errors of maximal flow and TLC were estimated and employed to obtain maximum likelihood estimates [39], yielding slopes and intercepts corrected for 
measurement errors. Differences between normal subjects, and asthmatic patients according to sex, treatment and bronchodilation were assessed using ANOVA of the mean slopes of these regression lines.

\section{Results}

Sixty-five patients (45 males) participated in the study. Baseline data are summarised in table 1. Pulmonary function indices at the start and end of the study are summarised in tables 2 and 3. Within a year of randomisation, six males

Table 1.-Baseline characteristics of both treatment groups prior to randomisation

\begin{tabular}{lcc}
\hline & BA+PL & BA+ICS \\
\hline Subjects n & 30 & 35 \\
F:M & $23: 7$ & $22: 13$ \\
Age yrs & $10.9 \pm 1.9$ & $11.4 \pm 2.1$ \\
Height cm & $145.9 \pm 12.0$ & $150.0 \pm 14.0$ \\
Weight kg & $36.3 \pm 11.4$ & $36.7 \pm 13.3$ \\
PD20 $\mu \mathrm{g}$ & $25.7(4.4-148)$ & $18.2(4.2-79.4)$ \\
\hline
\end{tabular}

Data are presented as mean \pm SD or geometric mean $(95 \% \mathrm{CI})$. BA+PL: $\beta_{2}$-agonist+placebo; BA+ICS: $\beta_{2}$-agonist+inhaled corticosteroids; F: female; M: male; PD20: provocative dose of histamine causing a $20 \%$ fall in forced expiratory volume in one second. receiving $\mathrm{BA}+\mathrm{PL}$ dropped out and could therefore not be included in the analyses; one male withdrew from the study for nonmedical reasons, five others demonstrated clinical deterioration requiring rescue medication too often. Because of a selective and significant dropout of patients inhaling $\mathrm{BA}+\mathrm{PL}$ an independent monitoring committee decided to discontinue the BA+PL treatment after a median follow-up of 22 months [32]. Hence, median follow-up in the BA+ICS group was longer than in the $\mathrm{BA}+\mathrm{PL}$ group. Clinical improvement was observed in patients taking $\mathrm{BA}+\mathrm{ICS}$, especially in the first 2 months [32]. Of the remaining group of 59 patients five were excluded (four on BA+PL) from the analyses because no growth of TLC was observed (due to early dropout or little growth at the end of puberty). The results relate to 34 patients receiving $\mathrm{BA}+\mathrm{ICS}$, and 20 patients taking $\mathrm{BA}+\mathrm{PL}$ who remained on the same treatment. The median (range) follow-up of patients on BA+ICS was longer: 2.9 (2.0-3.2) yrs, compared to those on BA+PL: 1.7 (0.8-2.2) yrs.

In healthy subjects RV/TLC in males and in females differed significantly: at the age of 11 yrs mean \pm SD RV/TLC was $18.0 \pm 5.3 \%$ and $20.0 \pm 4.7 \%$, respectively $(\mathrm{p}<0.001)$, with a mean \pm SD increase with age in both sexes of $0.7 \pm 1.3 \%$ per $y r$. In the two groups of patients RV/TLC decreased significantly after bronchodilation (table 2); the values before and after bronchodilation were similar for the sexes and larger than in healthy subjects: at age 11 the mean $(95 \% \mathrm{CI})$ difference in postbronchodilator RV/TLC between patients and healthy controls was $3.6(1.7-5.4) \%$ for males and $2.9(0.6-5.2) \%$ in

Table 2. - Pulmonary function indices expressed in \% predicted [35] or in \% at the start of the study

\begin{tabular}{|c|c|c|c|c|}
\hline & \multicolumn{2}{|r|}{$\mathrm{BA}+\mathrm{PL}(\mathrm{n}=20)$} & \multicolumn{2}{|r|}{$\mathrm{BA}+\mathrm{ICS}(\mathrm{n}=34)$} \\
\hline & Baseline & After maximal bronchodilation & Baseline & After maximal bronchodilation \\
\hline PEF \% pred & $86.0 \pm 17.8$ & $101.8 \pm 15.1^{\#}$ & $87.0 \pm 15.0$ & $105.1 \pm 15.9^{\#}$ \\
\hline FEV1 \% pred & $73.5 \pm 13.7$ & $92.1 \pm 11.3^{\#}$ & $72.2 \pm 11.4$ & $93.1 \pm 12.7^{\#}$ \\
\hline FVC $\%$ pred & $88.3 \pm 12.5$ & $95.6 \pm 11.6^{\#}$ & $86.2 \pm 11.1$ & $94.0 \pm 12.4^{\#}$ \\
\hline MMEF \% pred & $46.1 \pm 14.3$ & $74.7 \pm 17.8^{\#}$ & $45.3 \pm 11.2$ & $78.4 \pm 16.1^{\#}$ \\
\hline TLC $\%$ pred & $99.3 \pm 9.2$ & $99.4 \pm 10.8$ & $96.9 \pm 11.7$ & $97.4 \pm 12.9$ \\
\hline MEF60\%TLC/TLC $\%$ & $41.6 \pm 16.6$ & $71.0 \pm 20.9^{\#}$ & $41.7 \pm 19.9$ & $72.3 \pm 22.0^{\#}$ \\
\hline MEF $40 \%$ TLC/TLC $\%$ & $14.8 \pm 8.7$ & $31.8 \pm 11.8^{\#}$ & $15.4 \pm 15.3$ & $33.1 \pm 14.7^{\#}$ \\
\hline $\mathrm{FEV} 1 / \mathrm{FVC} \%$ & $69.8 \pm 8.6$ & $81.3 \pm 7.0^{\#}$ & $70.4 \pm 5.5$ & $83.4 \pm 5.2^{\#}$ \\
\hline FEV $1 /$ TLC $\%$ & $52.3 \pm 8.2$ & $64.3 \pm 6.3^{\#}$ & $51.7 \pm 8.5$ & $64.4 \pm 7.8^{\#}$ \\
\hline $\mathrm{RV} / \mathrm{TLC} \%$ & $28.4 \pm 6.7$ & $22.6 \pm 4.9^{\#}$ & $29.5 \pm 8.0$ & $22.3 \pm 4.9^{\#}$ \\
\hline
\end{tabular}

BA+PL: $\beta_{2}$-agonist+placebo; BA+ICS: $\beta_{2}$-agonist+inhaled corticosteroids; PEF: peak expiratory flow; FEV1: forced expiratory volume in one second; FVC: forced vital capacity; MMEF: maximal mid-expiratory flow; TLC: total lung capacity; MEF60\%TLC, MEF60\%TLC: maximum expiratory flow at $60 \%$ or $40 \%$ of TLC, respectively; RV: residual volume; ${ }^{\#}$ : paired t-tests, $\mathrm{p}<0.0001$.

Table 3. - Pulmonary function indices expressed in \% predicted [35] or in \% at the end of the study

\begin{tabular}{|c|c|c|c|c|}
\hline & \multicolumn{2}{|r|}{$\mathrm{BA}+\mathrm{PL}(\mathrm{n}=20)$} & \multicolumn{2}{|r|}{$\mathrm{BA}+\mathrm{ICS}(\mathrm{n}=34)$} \\
\hline & Baseline & After maximal bronchodilation & Baseline & After maximal bronchodilation \\
\hline PEF ( $\%$ pred $)$ & $83.1(15.0)$ & $107.2(20.1)^{\#}$ & $105.3(18.0)$ & $114.7(16.5)^{\#}$ \\
\hline FEV1 (\% pred) & $72.1(13.9)$ & $94.8(10.5)^{\#}$ & $88.8(14.9)$ & $95.9(21.4)^{\#}$ \\
\hline FVC ( $\%$ pred $)$ & $88.3(12.1)$ & $97.0(10.8)^{\#}$ & $93.3(12.0)$ & $96.1(12.1)^{\#}$ \\
\hline MMEF (\% pred) & $28.4(10.6)$ & $50.1(12.9)^{\#}$ & $48.0(16.7)$ & $62.6(15.8)^{\#}$ \\
\hline TLC (\% pred) & $94.7(10.6)$ & $94.7(10.6)$ & $95.6(11.6)$ & $95.1(11.8)$ \\
\hline MEF60\%TLC/TLC \% & 34.7 (18.9) & $69.2(21.2)^{\#}$ & $61.1(25.5)$ & $82.4(24.3)^{\#}$ \\
\hline MEF $40 \%$ TLC/TLC $\%$ & $11.4(9.7)$ & $29.2(11.0)^{\#}$ & $24.6(14.9)$ & $36.3(15.4)^{\#}$ \\
\hline FEV1/FVC \% & $68.5(9.7)$ & $81.5(7.8)^{\#}$ & $78.6(7.2)$ & $85.9(5.1)^{\#}$ \\
\hline FEV1/TLC $\%$ & $48.2(10.3)$ & $63.0(6.4)^{\#}$ & $59.5(9.0)$ & $64.3(12.7)^{\#}$ \\
\hline RV/TLC \% & $33.5(9.0)$ & $27.0(6.5)^{\#}$ & $23.0(7.6)$ & $24.5(5.9)$ \\
\hline
\end{tabular}

BA+PL: $\beta_{2}$-agonist+placebo; BA+ICS: $\beta_{2}$-agonist+inhaled corticosteroids; PEF: peak expiratory flow; FEV1: forced expiratory volume in one second; FVC: forced vital capacity; MMEF: maximal mid-expiratory flow; TLC: total lung capacity; MEF60\%TLC, MEF60\%TLC: maximum expiratory flow at $60 \%$ or $40 \%$ of TLC, respectively; RV: residual volume; ${ }^{\sharp}$ : paired t-tests, $\mathrm{p}<0.0001$. 
females. The mean \pm SD longitudinal increase of prebronchodilator RV/TLC in patients (fig. 1) was different depending on treatment $(\mathrm{p}=0.007)$, but treatment did not significantly affect the evolution of postbronchodilator RV/TLC $(p=0.52)$. The mean \pm SD longitudinal increase of postbronchodilator $\mathrm{RV} /$ TLC in patients did not differ from that found in healthy subjects (power $88 \%$ ).

\section{Development of ventilatory function with age}

In healthy subjects, indices of airway calibre expressed as FEV $1 \%$ TLC, MEF60\%TLC $\left(\right.$ TLC $^{-1}$ s $^{-1}$ ) and MEF40\%TLC

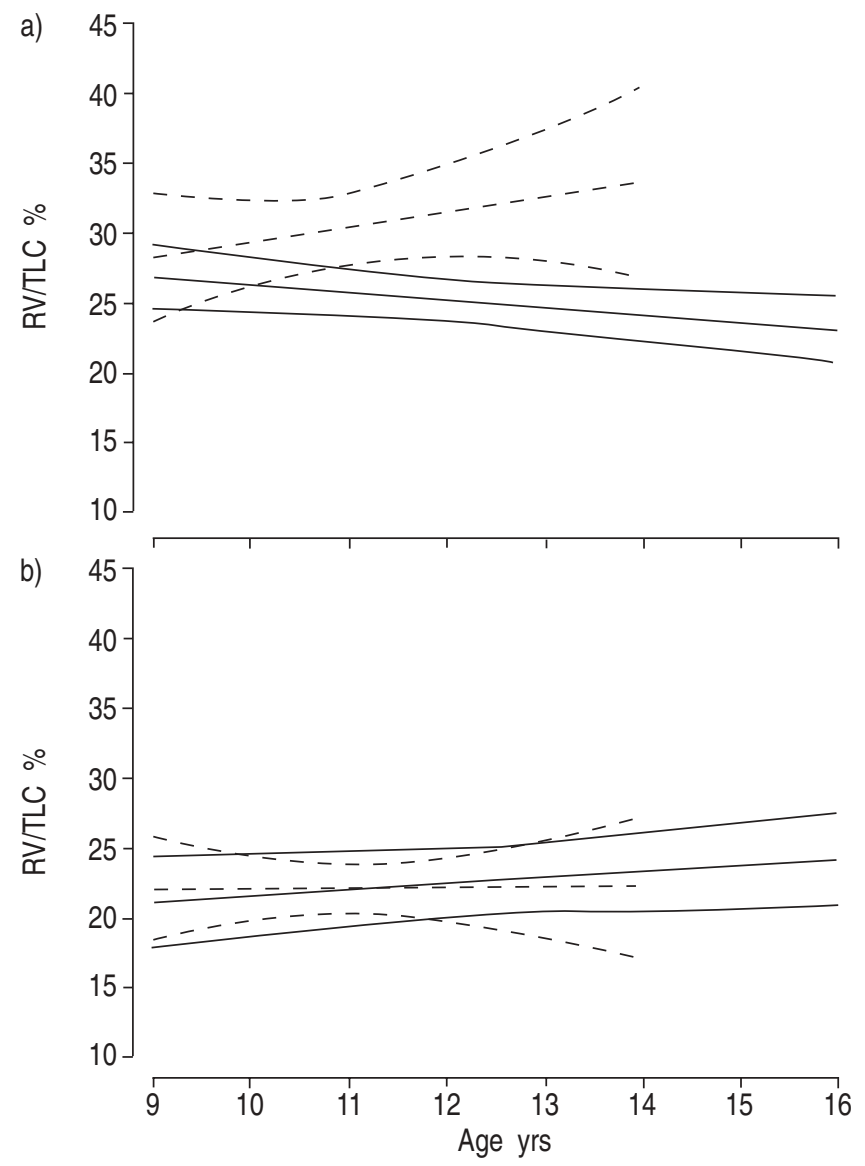

Fig. 1.- The effect of treatment on the longitudinal development of residual volume (RV)/total lung capacity (TLC) a) before and b) after bronchodilation. The solid lines refer to treatment with $\beta_{2}$-agonist (BA)+inhaled corticosteroids, the dashed lines refer to treatment with $\mathrm{BA}+$ placebo. Mean group trend and $95 \% \mathrm{CI}$ are given.
$\left(\mathrm{TLC} \cdot \mathrm{s}^{-1}\right)$ all declined significantly, and more so in females than in males (table 4, fig. 2). In patients receiving $\mathrm{BA}+\mathrm{PL}$ postbronchodilator flows remained below the normal range throughout the study, and the deficit was most pronounced for MEF40\%TLC. In patients inhaling BA+ICS postbronchodilator mean FEV1\%TLC and MEF60\%TLC fell generally in the normal range (figs 2a-d), unlike MEF40\%TLC (fig. 2e, f). Postbronchodilator FEV1\%TLC was similar for both treatment groups, but MEF60\%TLC and MEF40\%TLC was higher in patients on BA+ICS treatment. No difference between patients and healthy children could be demonstrated with respect to the longitudinal development of postbronchodilator FEV1\%TLC and MEF60\%TLC. MEF40\%TLC expressed as TLC $\cdot \mathrm{s}^{-1}$ declined faster in asthmatic males than in healthy males ( $\mathrm{p}=0.01$, table 4$)$. The changes of postbronchodilator measures of airway function were unrelated to treatment except for MEF40\%TLC which declined faster in patients taking $\mathrm{BA}+\mathrm{PL}$ than in those taking $\mathrm{BA}+\mathrm{ICS}$ (table 5, ANOVA, $\mathrm{p}=0.01$ ). The development of pre- and postbronchodilator indices of airway calibre was significantly different in patients taking BA+ICS from those on BA+PL (fig. 2). In the former, the difference between pre- and postbronchodilator airway calibre decreased whereas in patients on $\mathrm{BA}+\mathrm{PL}$ it either increased or remained similar during the study. Before randomisation, mean \pm SEM FEV1 following maximal bronchodilation increased $17.7 \pm 1.6 \%$ pred in $\mathrm{BA}+\mathrm{PL}$, and $20.4 \pm 1.4 \%$ pred in $\mathrm{BA}+\mathrm{ICS}$. At the end of the study, bronchodilator response in $\mathrm{BA}+\mathrm{PL}$ had increased to $22.7 \pm 2.4 \%$ pred $(\mathrm{p}=0.02)$ and bronchodilator response in the BA+ICS group had decreased to $11.6 \pm 1.5 \%$ pred $(\mathrm{p}<0.001)$. Mean \pm SD compliance with treatment in patients on $\mathrm{BA}+\mathrm{PL}$ was $430 \pm 180 \mu \mathrm{g}$ salbutamol and $470 \pm 240 \mu \mathrm{g}$ placebo, and in patients on BA+ICS this was $450 \pm 160 \mu \mathrm{g}$ salbutamol and $453 \pm 203 \mu \mathrm{g}$ budesonide, respectively, instead of $600 \mu \mathrm{g}$ daily, and did not change during the trial $(\mathrm{p}=0.15)$.

\section{Discussion}

Asthmatic inflammation of paediatric airways results in histological changes $[1-3,8]$ that may account for persisting functional abnormalities $[5,6,11,14,16,17]$ and progressive decline in prebronchodilator airway calibre in adult asthmatics $[5,7,15]$. This suggests that asthma is associated with progressive functional deterioration starting in childhood [21, 40], evolving into chronic obstructive lung disease [5, 9, 19]. The mechanisms involved may be related to changes such as diminished airway growth, changes of airway-parenchymal interdependence, altered airways mechanics due to remodelling, or phenomena such as enhanced bronchomotor tone and inflammatory swelling of the bronchial mucosa. If inflammation and/or remodelling affect growth of airway function

Table 4.-Longitudinal development of postbronchodilator measures of airway calibre with age between healthy subjects and patients according to sex

\begin{tabular}{|c|c|c|c|c|}
\hline Subjects/patients & Subjects $n$ & FEV1/TLC $\%$ per annum & MEF60\%TLC $\mathrm{TLC} \cdot \mathrm{s}^{-1}$ per annum & MEF40\% $\%$ LC TLC $\cdot \mathrm{s}^{-1}$ per annum \\
\hline \multicolumn{5}{|l|}{ Male children } \\
\hline Healthy & 311 & $-0.2 \pm 1.4$ & $-1.1 \pm 4.4$ & $-0.2 \pm 3.7$ \\
\hline Asthmatic & 36 & $-0.8 \pm 1.9$ & $-2.0 \pm 5.7$ & $-1.8 \pm 3.3^{\#}$ \\
\hline \multicolumn{5}{|l|}{ Female children } \\
\hline Healthy & 113 & $-0.5 \pm 1.1^{\uparrow}$ & $-2.2 \pm 4.2^{\oplus}$ & $-1.2 \pm 3.6^{\pi}$ \\
\hline Asthmatic & 18 & $-0.3 \pm 2.0$ & $-1.2 \pm 6.6$ & $-0.9 \pm 5.1$ \\
\hline
\end{tabular}

Data are presented as means \pm SD unless otherwise indicated; FEV1: forced expiratory yolume in one second; TLC: total lung capacity; MEF $60 \%$ TLC, MEF $40 \%$ TLC: maximum expiratory flow at $60 \%$ or $40 \%$ of TLC, respectively; ${ }^{\circ}$ : ANOVA, $p<0.02$ healthy female children compared to healthy male children; ": ANOVA, p=0.01 asthmatic male children compared to healthy male children. 

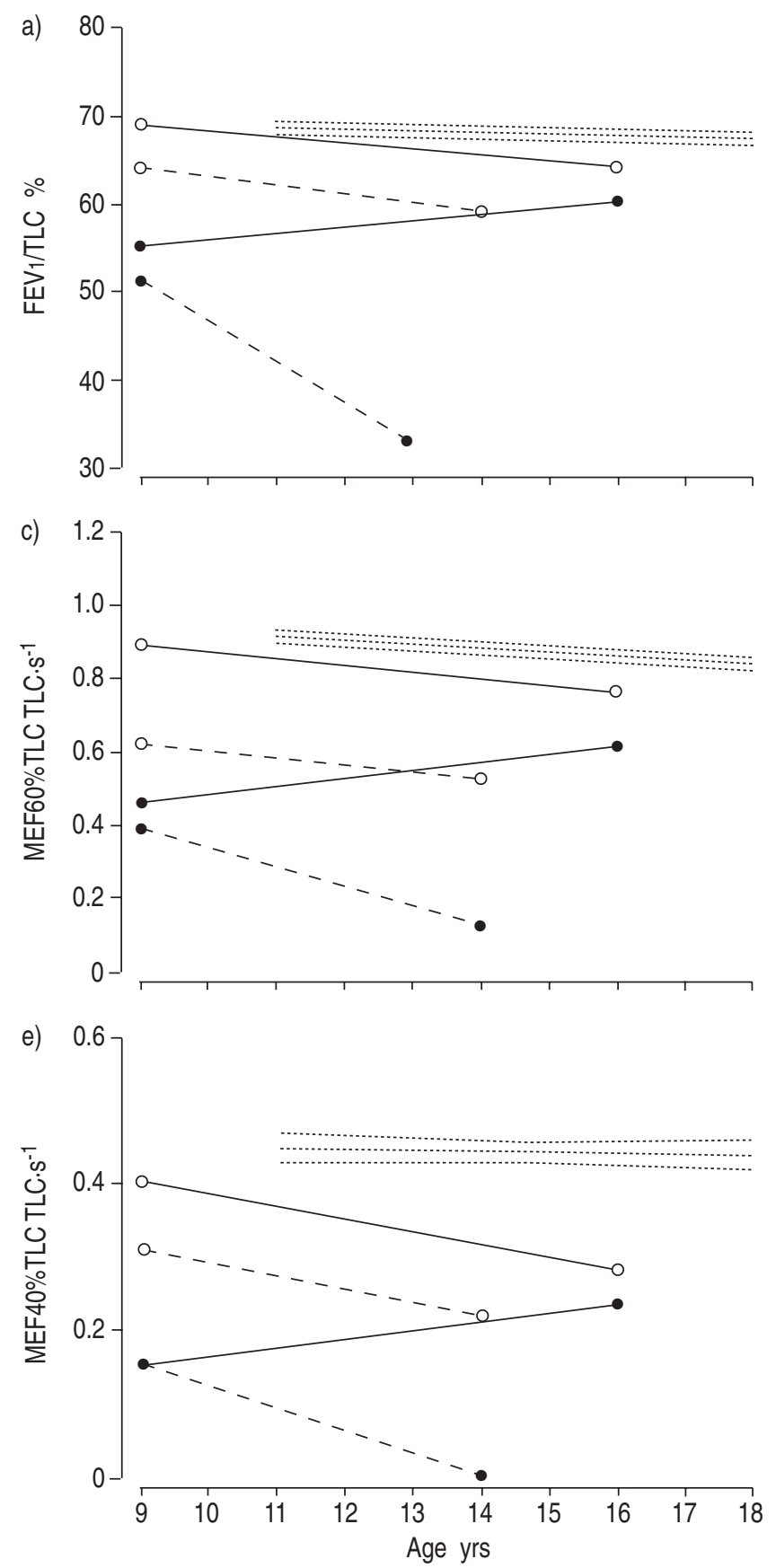

b)

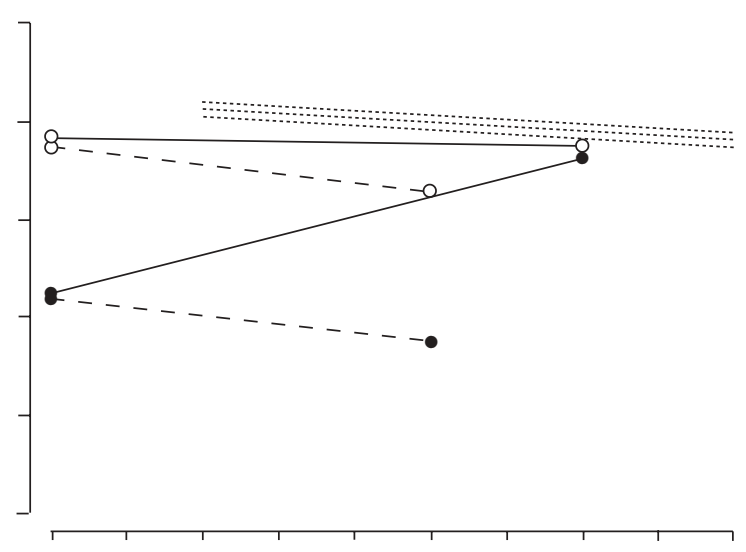

d)

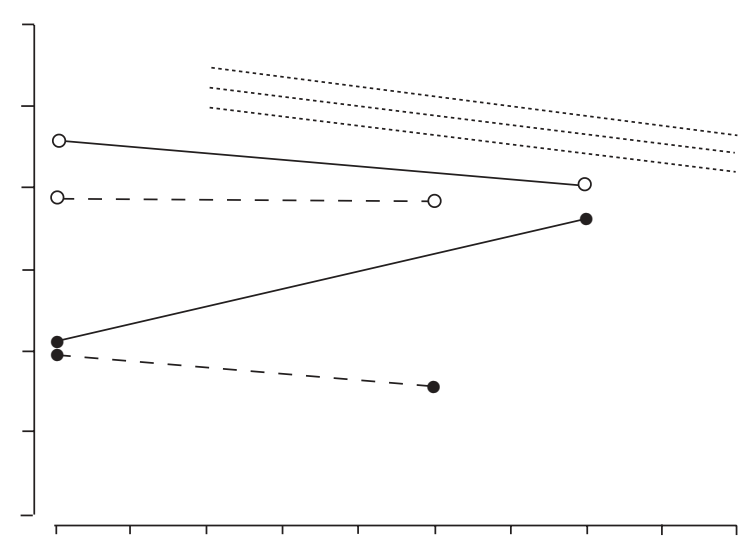

f)



Fig. 2. - a, b) Longitudinal development of forced expiratory volume in one second (FEV1)/total lung capacity (TLC) (\%) in a) males and b) females before and after maximal bronchodilation. c, d) Longitudinal development of maximum expiratory flow at $60 \%$ of TLC (MEF $60 \%$ TLC $\left(\right.$ TLC $\left.\cdot \mathrm{s}^{-1}\right)$ ) in c) asthmatic male children and d) asthmatic female children before and after maximal bronchodilation. e, f) Longitudinal development of MEF40\%TLC $\left(\mathrm{TLC} \cdot \mathrm{s}^{-1}\right)$ in e) asthmatic male children and f) asthmatic female children before and after maximal bronchodilation. Solid lines refer to the mean regression lines in patients receiving $\beta_{2}$-agonist (BA)+inhaled corticosteroids (ICS), dashed lines refer to the mean regression lines in patients receiving BA+placebo (PL). Lines connecting closed symbols (lower lines) refer to prebronchodilator data, lines connecting open symbols (upper lines) refer to postbronchodilator data. Dotted lines refer to the mean regression lines and $95 \% \mathrm{CI}$ in healthy subjects. Median follow-up of patients on BA+ICS was longer than in those on BA+PL (see text).

relative to lung parenchyma, but have an important reversible component, airway function may normalise by treatment with inhaled corticosteroids.

The current study found that in asthmatic children with no anti-inflammatory treatment $(\mathrm{BA}+\mathrm{PL})$, airway patency after maximal bronchodilation of central, intermediate and small airways remained reduced, with no signs of catch-up growth of airway function relative to lung volume. Randomised treatment with inhaled corticosteroids during nearly 2 yrs resulted in a significant and sustained improvement of preand postbronchodilator expiratory flows, while growth of central and intermediate airway function was not affected and remained similar to that found in healthy subjects. At the same time, symptom scores, bronchial hyperresponsiveness and exacerbation rates improved dramatically [32]. It therefore appears that, during growth, at high levels of lung inflation the combined effects of airway mechanics, airway calibre and lung elastic recoil on expiratory flow were the 
Table 5. - Annual change of postbronchodilator airway calibre in patients according to treatment and sex

\begin{tabular}{|c|c|c|c|c|}
\hline & Patients $\mathrm{n}$ & FEV1/TLC $\%$ & MEF60\%TLC $\%$ TLC $^{-1} \mathrm{~s}^{-1}$ & MEF $40 \%$ TLC $\%$ TLC $\cdot \mathrm{s}^{-1}$ \\
\hline \multicolumn{5}{|l|}{ Male children } \\
\hline $\mathrm{BA}+\mathrm{PL}$ & 15 & $-0.9 \pm 2.7$ & $-2.3 \pm 7.4$ & $-1.7 \pm 4.1$ \\
\hline $\mathrm{BA}+\mathrm{ICS}$ & 21 & $-0.7 \pm 1.0$ & $-1.8 \pm 4.4$ & $-1.7 \pm 2.9$ \\
\hline \multicolumn{5}{|c|}{ Female children } \\
\hline $\mathrm{BA}+\mathrm{PL}$ & 5 & $-0.9 \pm 2.5$ & $-0.2 \pm 6.3$ & $-1.9 \pm 5.3$ \\
\hline $\mathrm{BA}+\mathrm{ICS}$ & 13 & $-0.1 \pm 1.9$ & $-1.6 \pm 6.9$ & $-0.6 \pm 5.2$ \\
\hline \multicolumn{5}{|l|}{ ANOVA } \\
\hline Treatment & & 0.40 & 0.81 & 0.01 \\
\hline Sex & & 0.64 & 0.55 & 0.30 \\
\hline
\end{tabular}

Data are presented as means \pm SD unless otherwise indicated; BA+PL: $\beta_{2}$-agonist+placebo; $\mathrm{BA}+\mathrm{ICS}$ : $\beta_{2}$-agonist+inhaled corticosteroids; FEV1: forced expiratory volume in one second; TLC: total lung capacity; MEF $60 \%$ TLC, MEF $40 \%$ TLC: maximum expiratory flow at $60 \%$ or $40 \%$ of TLC, respectively.

same in patients on BA+ICS as in healthy subjects. However, because of the relatively small group of asthmatic children, this study probably lacks power to actually prove that level and development of FEV1\%TLC and MEF $60 \%$ TLC are very similar in patients and in controls. Furthermore, the differences in airway function between patients and controls is likely to be underestimated because the controls did not inhale bronchodilators. In addition, it cannot be excluded that stiffening of asthmatic airways [33, 41, 42] might compensate for irreversible airway narrowing due to remodelling. However these data suggest that normal functional development of major and intermediate airways can be achieved in children and adolescents with asthma on ICS maintenance treatment, and that these children can enter adulthood with a normal postbronchodilator FEV1, relative to lung size.

The present study further demonstrates that development of pre- and postbronchodilator lung function in asthmatic children can differ markedly, depending on the type of maintenance treatment. It also underlines that pre- and postbronchodilator vital capacity are biased estimates of lung size in asthma because RV/TLC in the patients was affected by bronchomotor tone and type of maintenance treatment. The decrease of prebronchodilator RV/TLC in patients on BA+ICS illustrates improvement of airway closure in that group. These findings are consistent with the evolution of other indices of airway calibre that differed according to treatment. In patients on $\mathrm{BA}+\mathrm{PL}$ bronchodilator responses were unaffected or increased, whereas in patients on BA+ICS prebronchodilator airway calibre improved progressively, and the difference with postbronchodilator airway calibre diminished. Thus, inhaled corticosteroids also acted as indirect bronchodilators. It should be mentioned here that these treatment effects may be underestimated because of a selective dropout of patients on $\mathrm{BA}+\mathrm{PL}$ with more severe respiratory symptoms (leading to discontinuation of the BA+PL treatment after a median follow-up of 22 months), with patients remaining in the $\mathrm{BA}+\mathrm{PL}$ treatment group with less severe asthma than those in the BA+ICS group [32].

However, in all patients, including those receiving BA $+\mathrm{ICS}$, peripheral airway function as assessed from MEF $40 \%$ TLC after maximal bronchodilation was reduced and remained below that in controls. Furthermore, airway closure as assessed from postbronchodilator RV/TLC was increased compared to healthy subjects, remaining abnormal in spite of good adherence to anti-inflammatory treatment. These persisting abnormalities are unlikely to be due to elevated bronchomotor tone, as the protocol involved maximal bronchodilation. Moreover, they may even be underestimated because in healthy subjects lung function was assessed without bronchodilation. They may reflect irreversible changes, or may indicate that the dose and/or the deposition of budesonide was insufficient to completely abolish peripheral airway wall inflammation; possibly, MEF $40 \%$ TLC and RV/TLC might have improved further with higher topical dosages. The effects of budesonide observed in the present study were due to an average daily intake of $0.45 \mathrm{mg}$ rather than the prescribed $0.6 \mathrm{mg}$, and not associated with significant systemic side-effects [43]. If bronchial hyperresponsiveness reflects airway inflammation, there would indeed be some indication that the patients on BA+ICS still had active airway inflammation: PD20 was still improving but had not normalised in patients on BA+ICS after a median follow-up of 22 months [32]. In spite of this, the large majority of patients on BA+ICS became asymptomatic during the trial [32], implying that these residual functional abnormalities may be statistically significant, but not clinically relevant during childhood and adolescence.

To the best of the authors' knowledge, this is the first study employing both maximal bronchodilation, and randomised treatment with a fixed dose of inhaled corticosteroids, irrespective of respiratory symptoms. The only two longitudinal studies that involved placebo-controlled anti-inflammatory treatment and postbronchodilator lung function tests are the Childhood Asthma Management Program (CAMP) study [22] and the Inhaled Steroid Treatment as Regular Therapy in Early Asthma (START) study [40]. The current study's conclusions are in contrast to those of the CAMP study, in which administration of anti-inflammatory treatment to children with mild asthma resulted in improved bronchial hyperresponsiveness and symptom scores, reduced exacerbation rates and use of rescue medication, and an improvement of prebronchodilator FEV1 but not postbronchodilator FEV1. In contrast to the present study, in the CAMP study, bronchodilation was not maximal, children had less severe asthma, the prescribed daily corticosteroid dose was $200 \mu \mathrm{g}$, and it allowed corticosteroid treatment to taper off or stop when symptoms improved, in line with international guidelines [34]. This may explain why no beneficial effect of inhaled corticosteroids was observed in the CAMP study on postbronchodilator FEV1 compared to placebo treatment. In the START study [40], children also had less severe asthma, prescribed daily corticosteroid dose was 200 or $400 \mu \mathrm{g}$, and the improvement of pre- and postbronchodilator FEV1 was significant, but not clinically relevant, ( $<3 \%$ of pred). Furthermore, in the CAMP and START study, compliance with treatment was not monitored, while in the current work patients and their parents were aware that compliance was monitored. Hence, the design of the studies, the asthma severity and the differences in endpoints make these studies difficult to compare.

In conclusion, in spite of the small sample size and the methodological limitations of the present study, the conclusion remains that residual functional abnormalities are 
present in asymptomatic asthmatic children, even when a daily dose of $600 \mu \mathrm{g}$ budesonide is prescribed and bronchomotor tone is completely abolished. This suggests that anti-inflammatory treatment of asthmatic children based on symptoms alone is not enough to result in normalisation of postbronchodilator airway function. As in adults [44], treatment with inhaled corticosteroids based on inflammatory markers may be needed to further reduce airway inflammation, improve peripheral airway function and to achieve optimal postbronchodilator lung function at the end of adolescence. Whether such treatment of asthmatic children in the absence of respiratory symptoms is realistic and can be ethically justified is open to debate, and whether it is required for optimal long-term prognosis remains to be shown.

Acknowledgements. The authors thank the children and their parents for their contribution, and AstraZeneca, Boehringer Ingelheim and GlaxoSmithKline for providing free study medication.

\section{References}

1. Barbato A, Turato G, Baraldo S, et al. Airway inflammation in childhood asthma. Am J Respir Crit Care Med 2003; 168: 798-803.

2. Jenkins HA, Cool C, Szefler SJ, et al. Histopathology of severe childhood asthma: a case series. Chest 2003; 124: 32 41.

3. Payne DN, Rogers AV, Adelroth E, et al. Early thickening of the reticular basement membrane in children with difficult asthma. Am J Respir Crit Care Med 2003; 167: 78-82.

4. Blair H. Natural history of childhood asthma. 20-year follow-up. Arch Dis Child 1977; 52: 613-619.

5. Grol MH, Gerritsen J, Vonk JM, et al. Risk factors for growth and decline of lung function in asthmatic individuals up to age 42 years. A 30-year follow-up study. Am J Respir Crit Care Med 1999; 160: 1830-1877.

6. Phelan PD, Robertson CF, Olinsky A. The Melbourne Asthma Study: 1964-1999. J Allergy Clin Immunol 2002; 109: 189-194.

7. Schachter EN, Doyle CA, Beck GJ. A prospective study of asthma in a rural community. Chest 1984; 85: 623-630.

8. van den Toorn LM, Overbeek SE, de Jongste JC, Leman K, Hoogsteden HC, Prins JB. Airway inflammation is present during clinical remission of atopic asthma. Am J Respir Crit Care Med 2001; 164: 2107-2113.

9. Bousquet J, Jeffery PK, Busse WW, Johnson M, Vignola AM. Asthma. From bronchoconstriction to airways inflammation and remodelling. Am J Respir Crit Care Med 2000; 161: $1720-1745$.

10. Kerrebijn KF, Fioole AC, van Bentveld RDW. Lung function in asthmatic children after a year or more without symptoms or treatment. $\mathrm{Br}$ Med $J$ 1978; 1: 886-888.

11. Woolcock AJ, Peat JK, Leeder SR, Blackburn CRB. The development of lung function in Sydney school children: effects of respiratory illness and smoking. Eur J Respir Dis 1984; 65: 1-137.

12. Greaves IA, Colebatch HJH. Large lungs after childhood asthma: a consequence of enlarged airspaces. Aus NZ J Med 1985; 15: 427-434.

13. Merkus PJ, van Essen-Zandvliet EE, Kouwenberg JM, et al. Large lungs after childhood asthma. A case-control study. Am Rev Respir Dis 1993; 148: 1484-1489.

14. Weiss ST, Tosteson TD, Segal MR, Tager IB, Redline S, Speizer FE. Effects of asthma on pulmonary function in children. A longitudinal population-based study. Am Rev Respir Dis 1992; 145: 58-64.

15. Peat JK, Woolcock AJ, Cullen K. Rate of decline of lung function in subjects with asthma. Eur J Respir Dis 1987; 70: 171-179.
16. Braman SS, Kaemmerlen JT, Davis SM. Asthma in the elderly. A comparison between patients with recently acquired and long-standing disease. Am Rev Respir Dis 1991; 143: 336340 .

17. Brown PJ, Greville HW, Finucane KE. Asthma and irreversible airflow obstruction. Thorax 1984; 39: 131-136.

18. Bousquet J, Chanez P, Lacoste JY, et al. Asthma: a disease remodeling the airways. Allergy 1992; 47: 3-11.

19. Konig P. Irreversible airway obstruction in childhood asthma? A clinician's viewpoint. Pediatr Pulmonol 2002; 33: 307-310.

20. Rasmussen F, Taylor DR, Flannery EM, et al. Risk factors for airway remodeling in asthma manifested by a low postbronchodilator FEV(1)/vital capacity ratio: a longitudinal population study from childhood to adulthood. $\mathrm{Am}$ J Respir Crit Care Med 2002; 165: 1480-1488.

21. Agertoft L, Pedersen S. Effects of long-term treatment with an inhaled corticosteroid on growth and pulmonary function in asthmatic children. Respir Med 1994; 88: 373-381.

22. The CAMP research group. Long-term effects of budesonide or nedocromil in children with asthma. The Childhood Asthma Management Program Research Group. N Engl $J$ Med 2000; 343: 1054-1063.

23. Zeiger RS, Dawson C, Weiss S. Relationships between duration of asthma and asthma severity among children in the Childhood Asthma Management Program (CAMP). J Allergy Clin Immunol 1999; 103: 376-387.

24. Sherril D, Sears MR, Lebowitz MD, et al. The effects of airway hyperresponsiveness, wheezing and atopy on longitudinal pulmonary function in children: A 6-year follow-up study. Pediatr Pulmonol 1992; 13: 78-85.

25. Berhane $\mathrm{K}$, McConnell R, Gilliland F, et al. Sex-specific effects of asthma on pulmonary function in children. $\mathrm{Am}$ J Respir Crit Care Med 2000; 162: 1723-1730.

26. Borsboom GJJM, van Pelt W, Quanjer PhH. Pubertal growth curves of ventilatory function: relationship with childhood respiratory symptoms. Am Rev Respir Dis 1993; 147: 372-378.

27. Merkus PJ, Tiddens HA, de Jongste JC. Annual lung function changes in young patients with chronic lung disease. Eur Respir $J$ 2002; 19: 886-891.

28. Balfour-Lynn L. Growth and childhood asthma. Arch Dis Child 1986; 61: 1049-1055.

29. DeGroodt EG, van Pelt W, Quanjer PhH, van Zomeren BC, Borsboom GJJM. The growth of lung and thorax dimensions during the pubertal growth spurt. Eur Respir J 1988; 1: 102-108.

30. Martin TR, Feldman HA, Fredberg JJ, Castile RG, Mead J, Beck Wohl ME. Relationship between maximal expiratory flows and lung volumes in growing humans. J Appl Physiol 1989; 65: 822-828.

31. Merkus PJ, Borsboom GJ, Van Pelt W, et al. Growth of airways and air spaces in teenagers is related to sex but not to symptoms. J Appl Physiol 1993; 75: 2045-2053.

32. van Essen-Zandvliet EE, Hughes MD, Waalkens HJ, Duiverman EJ, Pocock SJ, Kerrebijn KF. Effects of 22 months of treatment with inhaled corticosteroids and/or beta-2-agonists on lung function, airway responsiveness, and symptoms in children with asthma. The Dutch Chronic Nonspecific Lung Disease Study Group. Am Rev Respir Dis 1992; 146: 547-554.

33. Brackel HJ, Pedersen OF, Mulder PG, Overbeek SE, Kerrebijn KF, Bogaard JM. Central airways behave more stiffly during forced expiration in patients with asthma. Am J Respir Crit Care Med 2000; 162: 896-904.

34. Warner JO, Naspitz CK. Third International Pediatric Consensus statement on the management of childhood asthma. International Pediatric Asthma Consensus Group. Pediatr Pulmonol 1998; 25: 1-17.

35. Zapletal A, Paul T, Samanek M. Die Bedeutung heutiger Methoden der Lungenfunktionsdiagnostik zur Feststellung einer Obstruktion der Atemwege bei Kindern und Jugendlichen [Significance of contemporary methods of 
lung function testing for the detection of airway obstruction in children and adolescents]. Z Erkrankungen Atm-Org 1977; 149: 343-371.

36. Merkus PJFM, Eelkman Rooda HM, van Essen-Zandvliet EEM, Duiverman EJ, Quanjer PhH, Kerrebijn KF. Assessment of bronchodilatation following spontaneous recovery from a histamine challenge in asthmatic children. Thorax 1992; 47: 355-359.

37. Merkus PJFM, Verver S, van Essen-Zandvliet EEM, Duiverman EJ, Kerrebijn KF, Quanjer PhH. Lung volumes measured by the forced rebreathing technique in children with airways obstruction. Eur Respir J 1992; 5: 879-886.

38. Sterk PJ, Quanjer PhH, Van der Maas LLJ, Wise ME, van der Lende R. The validity of the single breath nitrogen determination of residual volume. Bull Eur Physiopath Resp 1980; 16: 195-213.

39. Kendall SM, Stuart A. Functional and structural relationship. In: The Advanced Theory of Statistics Vol. 2. Inference and relationship. London, Griffin, 1979; pp. 399-343.
40. Pauwels RA, Pedersen S, Busse WW, et al. Early intervention with budesonide in mild persistent asthma: a randomised, double-blind trial. Lancet 2003; 361: 1071-1076.

41. Wilson JW, Li X, Pain MC. The lack of distensibility of asthmatic airways. Am Rev Respir Dis 1993; 148: 806-809.

42. Ward C, Johns DP, Bish R, et al. Reduced airway distensibility, fixed airflow limitation, and airway wall remodeling in asthma. Am J Respir Crit Care Med 2001; 164: 18-21.

43. Merkus PJ, van Essen-Zandvliet EE, Duiverman EJ, van Houwelingen HC, Kerrebijn KF, Quanjer PH. Long-term effect of inhaled corticosteroids on growth rate in adolescents with asthma. Pediatrics 1993; 91: 1121-1126.

44. Sont JK, Willems LN, Bel EH, van Krieken JH, Vandenbroucke JP, Sterk PJ. Clinical control and histopathologic outcome of asthma when using airway hyperresponsiveness as an additional guide to long-term treatment. The AMPUL Study Group. Am J Respir Crit Care Med 1999; 159: 10431051. 